\title{
KOMUNIKASI INTERPERSONAL DALAM MANAJEMEN ORGANISASI MUHAMMADIYAH DI PANGANDARAN
}

\section{INTERPERSONAL COMMUNICATION IN MUHAMMADIYAH ORGANIZATION MANAGEMENT IN PANGANDARAN}

\author{
Nandhini Hudha Anggarasari ${ }^{1}$ dan Milah Nurkamilah ${ }^{2}$ \\ ${ }^{12}$ Universitas Muhammadiyah Tasikmalaya \\ E-mail: nandhini.hagrs@umtas.ac.id dan milah.nurkamilah@umtas.ac.id
}

\begin{abstract}
ABSTRAKS
Penelitian ini bertujuan untuk mengetahui komunikasi interpersonal dalam manajemen organisasi Muhammadiyah di Pangandaran. Manfaat penelitian adalah agar dapat menjadi salah satu acuan dalam merumuskan langkah kebijakan dan program kerja organisasi Muhammadiyah di Pangandaran. Teknik pengambilan subjek yang digunakan adalah metode stratified sampling. Metode penelitian ini dengan survey dan kualitatif wawancara. Subjek penelitian adalah warga muhammadiyah di Pangandaran dan masyarakat umum. Berdasarkan hasil survey angket, kategori rata-rata komunikasi interpersonal pada warga Muhamamdiyah adalah 19,4, yang mengindikasikan bahwa warga Muhammadiyah memiliki komunikasi interpersonal yang baik. Namun berdasarkan hasil wawancara, ada beberapa hal yang ditemukan antara lain kurangnya komunikasi interpersonal antar warga dan pimpinan yang mengakibatkan kesalahpahaman dalam menjalankan organisasi dan kurangnya melakukan komunikasi dan interaksi sosial dengan masyarakat.
\end{abstract}

Kata Kunci : Komunikasi Interpersonal, Manajemen, Organisasi Muhammadiyah.

\begin{abstract}
This study aims to determine the interpersonal communication in Muhammadiyah organization management in Pangandaran. The benefit of the research is to be the one of the reference in formulating the policy and work program of Muhammadiyah organization in Pangandaran. The technique of taking the subject used is stratified sampling method. This research method with survey and qualitative interview. The subjects of the study were Muhammadiyah residents in Pangandaran and the general public. Based on the questionnaire survey, the interpersonal communication category among the Muhamamdiyah residents is 19,4 , which indicates that Muhammadiyah people have good interpersonal communication. However, based on interview results, there are several things found, among others, lack of interpersonal communication between citizens and leaders that lead to misunderstandings in running the organization and lack of communication and social interaction with the community.
\end{abstract}

Keywords :Interpersonal Communication, Management, Muhammadiyah Organization. 


\section{PENDAHULUAN}

Muhammadiyah adalah salah satu persyarikatan di dunia, yang memiliki organiasi Muhamamdiyah yang berpusat di Yogyakarta dan Jakarta. Setiap Pimpinan di wilayah, daerah, cabang dan ranting, membawahi majelis-majelis, lembaga, badan, dan biro. Namun tidak menutup kemungkinan pimpinan wialayah,daerah, cabang, dan ranting bekerja sama dengan organisasi otonom yang terdiri dari pemuda Muhammadiyah, Hizbul Wathan, Tapak, Suci, IMM, IPM, NA, dan Aisyiyah.

Muhammadiyah tersebar di seluruh penjuru nusantara, termasuk di Jawa Barat. Beberapa wilayah di Jawa Barat mengalami pemekaran, salah satunya adalah Pangandaran dari kabupaten Ciamis, pada tanggal 25 Oktober 2012. Pemekaran dan otonomi daerah berdampak pula pada pendirian organisasi Muhammadiyah yang baru, yaitu Muhammadiyah Pangandaran. Proses pendirian organisasi Muhammadiyah yang baru yang meliputi sepuluh kecamatan dan luas wilayah $1680 \mathrm{~km}^{2}$ bukanlah sebuah perkara yang mudah. Perlu adanya komitmen yang kuat, komunikasi dan kesungguhan dari semua warga Muhammadiyah untuk mewujudkan manajemen yang baik.

Berdasarkan hasil observasi pendahuluan yang dilakukan peneliti, dalam kurun waktu enam tahun tidak ada perubahan dalam pengembangan amal usaha Muhammadiyah, tida ada pula perubahan jumlah kader Muhammadiyah, bahkan pengajian dan kegiatan sosial di tingkat ranting cenderung vakum.

Berdasarkan hasil wawancara pendahuluan yang dilakukan peneliti, ditemukan bahwa masyarakat di Kabupaten Pangandaran termasuk masyarakat yang majemuk, ada yang merupakan warga asli dan warga pendatang. Banyak masyarakat yang masih melakukan tradisi budaya yang menurut beliau kurang sesuai dengan syariat islam. Misalnya percaya tentang klenik, percaya tentang hari baik dan buruk, dan lain-lain. Banyak masyarakat yang masih perlu dibina tentang nilai-nilai keislaman dan diarahkan sesuai dengan syariat islam. Namun disisi lain, antar warga muhammadiyah sendiri ada kendala yaitu kurangnya komunikasi antar ortom dan kurangnya membangun inisiatif untuk saling kerja sama antar ortom. Selain itu juga kecenderungan warga Muhammadiyah di Pangandaran yang lebih suka memandang segala sesuatu dengan materi, kurng adanya jiwa sukarela dan mau bekerja sama lembaga dan persyarikatan.

Penelitian ini bertujuan untuk mengetahui komunikasi interpersonal pada warga Muhammadiyah dalam menjalankan manajemen organisasi dan dampaknya pada masyarakat Pangandaran. Manfaat penelitian ini adalah sebagai salah satu acuan dalam 
membuat kebijakan dan program kerja organisasi Muhammadiyah selanjutnya.

\section{Komunikasi Interpersonal}

Komunikasi antar pribadi atau interpersonal adalah komunikasi yang dilakukan oleh dua orang atau lebih secara langsung dan saling bertatap muka, yang saling memberi dan menerima informasi atau pesan secara verbal ataupun non verbal, yang memberikan dampak dan peluang untuk saling memberikan umpan balik yang dapat mempengaruhi sikap, pendapat, atau perilaku manusia (Anggarasari, 2012). Komunikasi antarpribadi atau interpersonal dapat dikategorikan menjadi dua karakteristik penting yaitu berlangsung beberapa tahap dan berbeda-beda dalam hal keluasan dan kedalaman. Tahap-tahap dalam komunikasi interpersonal yaitu kontak, keterlibatan, keakraban, perusakan, dan pemutusan. (Rakhmat,2005).

Dalam tahap kontak dengan orang lain, individu akan menggunakan alat indra sebagai media. Indra penglihatan, pendengaran, dan penciuman. Dalam tahap ini, penampilan fisik itu penting sekali. Namun, adanya sikap terbuka, bersahabat, hangat, dan dinamis akan membantu dalam kelangsungan komunikasi interpersonal, sehingga akan masuk pada tahap selanjutnya yaitu keterlibatan. Pada tahap keterlibatan, individu ada keterikatan satu sama lain untuk saling terbuka dan belajar untuk mengenal lebih jauh orang lain. Pada tahap ini timbul hubungan persahabatan dan kencan. Pada tahap keakraban, orang akan mengikat lebih jauh dan mungkin membina hubungan primer, dimana orang lain menjadi sahabat baik atau kekasih. Komitmen ini mempunyai berbagai bentuk seperti perkawinan dan persahabatan.

Tahap perusakan merupakan tahap penurunan hubungan. Biasanya terjadi karena harapan individu tidak sesuai dengan kenyataan, ataupun jarang bertemu dengan orang tersebut, dan ketika bertemu lebih banyak berdiam diri daripada saling terbuka. Jika tahap ini tidak diperbaiki, maka akan masuk tahap pemutusan. Tahap pemutusan adalah pemutusan ikatan yang mempertalikan kedua pihak. Jika bentuk iktan itu berupa perkawinan, maka pemutusan hubungan itu dilambangkan dengan perceraian.

De Vito (Liliweri,1997) mengemukakan bahwa komunikasi interpersonal mengandung lima ciri yaitu, keterbukaan atau opennes, empati, dukungan, perasan positif, dan adanya kesamaan. Komunikasi yang efektif antar warga Muhammadiyah untuk memulai mendirikan organisasi Muhamamdiyah di Pangandaran idealnya diawali dengan adanya keterbukaan satu sama lain, baik kelebihan maupun kekurangannya, agar 
dapat saling melengkapi. Setiap warga saling mendukung dan berprasangka positif untuk bertindak dan melakukan tujuan kegiatan yang sama.setiap warga Muhammadiyah idealnya saling melakukan kontak dan terlibat dalam setiap aspek kegiatan guna pengembangan organisasi yang lebih baik.

\section{Manajemen Organisasi}

Organisasi memiliki lima pilar yang menjadi komponen dasar yaitu product, marketing, finance, SDM. (Syahid, 2017). Dalam menjalankan organisasi perlu memperhatikan adanya barang atau jasa yang dihasilkan dalam bentuk product berupa karya, pelatihan, ataupun kegiatan yang bermanfaat. Marketing dalam organisasi meliputi tentang segenap daya yang dibutuhkan dan diolah menjadi sesuatu yang berharga bagi pengembangan organisasi, yang terdiri dari perencanaan, proses, hingga evaluasi. Finance dalam organisasi menelaah tentang keluar masuknya dana baik melalui penanaman modal, hibah, penjualan produk, dan hutang. SDM (Sumber Daya Manusia) meliputi segenap aspek pengembangan daya manusia untuk seseorng yang lebih bermanfaat bagi sesama.

Menurut Fachruddin (2009), pengembangan sumber daya manusia perlu dilakukan perencanaan secara sistematis mulai dari menggali kekuatan yang ada, hingga tahapan selanjutnya hingga potensi yang ada dapat baik secara maksimal.

Menurut Stoner (Fachruddin, 2009), manajemen adalah proses perencanaan, pengorganisasian, memimpin, dan mengawasi pekerjaan organisasi dan untuk menggunakan semua sumber daya organisasi yang tersedia untuk mencapai tujuan organisasi yang dinyatakan dengan jelas Manajemen meliputi tahap perencanaan, organizing, actuating, dan controlling.

Organisasi Muhammadiyah memiliki cita-cita hidup yang tercantum dalam anggaran dasar dan anggaran rumah tangga. Komitmen awal sangat pentingdalam mendasari semuakegiatan Muhamamdiyah. Menurut penelitian Yudhi (2005), kepuasan anggota dalam organisasi akan meningkat bila dalam sebuah organisasi memiliki komitmen dan iklim organisasi yang baik. Iklim organisasi yang baik sangat erat kaitannya dengan proses manajemen dalam organisasi. Sehingga penting sekali komunikasi awal untuk menyamakan komitmen dan menyusun manajemen organisasi bersama-sama agar kinerja organisasi dapat berjalan dengan baik. 


\section{METODE PENELITIAN}

Populasi pada penelitian ini yaitu seluruh masyarakat di Kabupaten Pangandaran yang terdiri dari 10 Kecamatan. Adapun teknik sampling yang digunakan yaitu stratified sampling, dimana akan dipilih secara acak masyarakat yang mewakili dari tiap kecamatan.

Metode yang digunakan untuk pengumpulan data yaitu menggunakan wawancara dan instrumen angket. Instrumen ini berisi tentang persepsi masyarakat terhadap organisasi Muhammadiyah, peran Muhammadiyah dalam bidang sosial, komitmen, komunikasi, dan kesamaan visi dan misi.

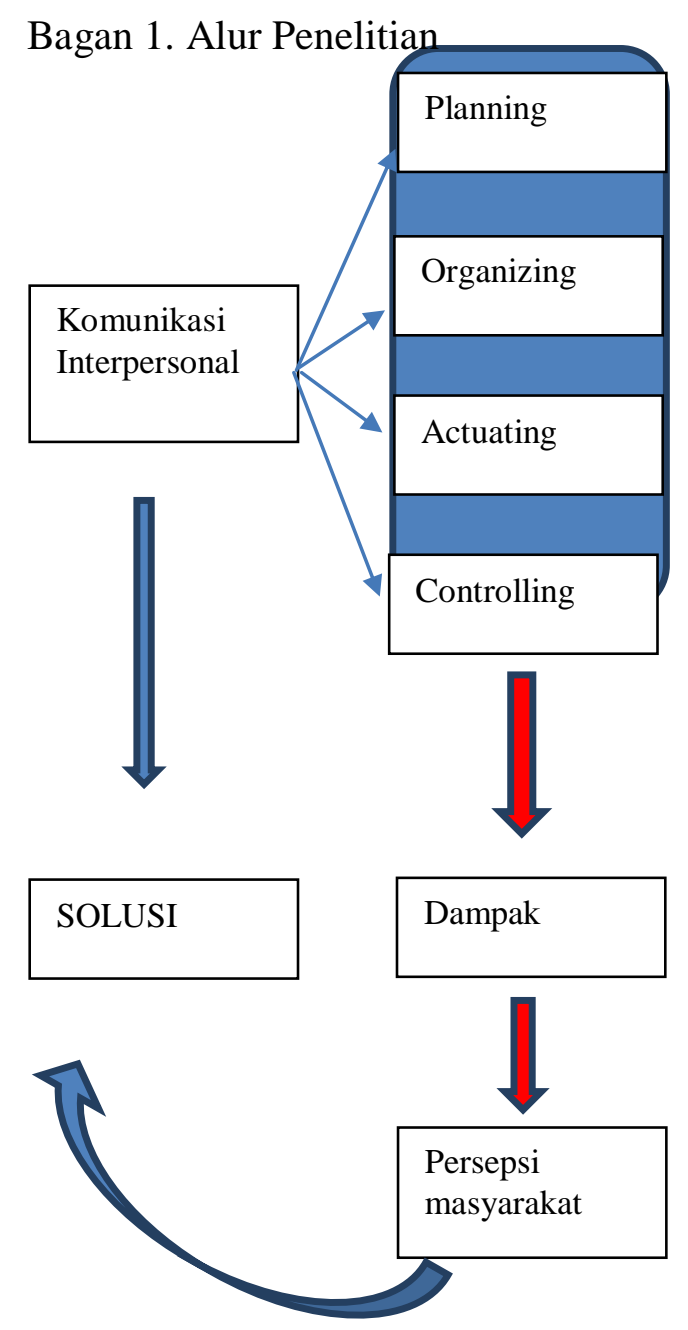




\section{HASIL DAN PEMBAHASAN}

Rumus yang digunakan dalam penelitian ini dibuat oleh Widoyoko (2015) berdasarkan table 1, yakni :

Tabel 1. Tabel kriteria persepsi Muhammadiyah

\begin{tabular}{|c|c|c|}
\hline Interval & Interval & Kriteria \\
\hline $\begin{array}{r}\mathrm{X}>x_{i}+ \\
1,8 \mathrm{sbi}\end{array}$ & $X>63$ & Sangat baik \\
\hline $\begin{array}{l}\overline{x_{i}}+0,6 \mathrm{sbi}<\mathrm{X} \leq \\
\overline{x_{i}}+1,8 \mathrm{sbi}\end{array}$ & $51<X \leq 63$ & Baik \\
\hline $\begin{array}{l}\overline{x_{i}}-0,6 \mathrm{sbi}<\mathrm{X} \leq \\
\overline{x_{i}}+0,6 \mathrm{sbi}\end{array}$ & $39<X \leq 51$ & Cukup \\
\hline $\begin{array}{l}\overline{x_{i}}-1,8 \text { sbi }<\mathrm{X} \leq \\
\overline{x_{i}}-0,6 \mathrm{sbi}\end{array}$ & $27<X \leq 39$ & Rendah \\
\hline $\begin{array}{r}\mathrm{X} \leq \overline{x_{i}} \\
-1,8 \mathrm{sbi}\end{array}$ & $X \leq 27$ & $\begin{array}{l}\text { Sangat } \\
\text { rendah }\end{array}$ \\
\hline
\end{tabular}

Berdasarkan data yang telah diolah, hasil uji angket pada warga Muhamamdiyah adalah sebagai berikut :

Tabel 2.Hasil Angket Persepsi Warga Muhammadiyah

\begin{tabular}{|c|c|c|}
\hline Indikator & $\begin{array}{c}\text { Rata- } \\
\text { Rata }\end{array}$ & Kriteria \\
\hline Komitmen & 16,33 & cukup \\
\hline Komunikasi & 19,44 & Baik \\
\hline Kesamaan Visi-Misi & 18,89 & Baik \\
\hline
\end{tabular}

Berdasarkan hasil uji angket yang disebar pada warga Muhammadiyah, menurut indikator yang dibuat Widoyoko (2015), nilai rata-rata komunikasi interpersonal diantara warga Muhammadiyah adalah 19,44, yang mengindikasikan kriteria yang baik. Warga Muhammadiyah memiliki komitmen 16,33, yang mengindikasikan kriteria cukup. Warga Muhammadiyah memiliki rata-rata kesamaan visi dan misi 18,89, yang mengindikasikan baik.

Berdasarkan hasil wawancara, komunikasi antar warga Muhammadiyah pada awalnya berjalan dengan baik, saling menerima dengan terbuka dan menjalin kontak satu sama lain, namun saat bersama-sama saling terlibat dalam sebuah kegiatan, berakhir 
menjadi kurang baik, hubungan menjadi renggang dan sebagian komunikasi mulai putus. Hal ini disebabkan karena tidak adanya aturan yang mendukung proses manajemen organisasi.

Proses manajemen organisasi yang diawali dengan perencanaan, belum pernah dilakukan secara menyeluruh antara pimpinan dan seluruh warga Muhammadiyah. Perencanaan hanya sebatas kegiatan-kegiatan yang bersifat kondisional dan sifatnya sementara. Belum ada penyusunan rencana dari rencana jangka pendek, menengah, hingga rencana jangka panjang. Hal ini cukup mempengaruhi komitmen awal warga Muhammadiyah, yang awalnya menjunjung tinggi motto, "Hidup hidupilah Muhamamdiyah, jangan mencari hidup di Muhamamdiyah", menjadi sebaliknya.

Sebagian warga yang melenceng dari cita-cita hidup dan ciri perjuangan Muhammadiyah, yang menjadi dasar visi dan misi dalam organisasi di Muhammadiyah, mulai mempengaruhi komitmen warga Muhammadiyah yang lainnya. Sebagian warga jadi enggan terlibat aktif dalam kegiatan Muhammadiyah secara menyeluruh.

Warga Muhammadiyah belum sepenuhnya duduk bersama untuk melakukan organizing. Klasifikasi tugas berdasarkan kemampuan dan potensi yang dimiliki jarang dilakukan oleh pimpinan Muhammadiyah. Selama ini hanya asal menunjuk dan membuatkan Surat Tugas tanpa mempertimbangkan pemetaan potensi warga yang ada. Hingga akhirnya ada beberapa amal usaha dikelola oleh satu keluarga besar warga Muhammadiyah, yang memberi dampak kecemburuan sosial dan hilangnya rasa empati dalam berkomunikasi antar pribadi. Penunjukan oleh pimpinan tanpa adanya diskripsi tugas yang jelas dan komunikasi antar warga, membuat divisi organisasi itu hanya sekedar "tumpang nama", yang tentunya akan mempengaruhi proses actuating.

Actuating dalam organisasi merupakan proses pelaksanaan organisasi yang membutuhkan kerja keras, kerja cerdas, dan kerja sama antar divisi. Proses ini akan berjalan lebih baik jika adanya komunikasi interpersonal yang baik pula. Namun ketidaktahuan diskripsi tugas dan ketiadaan prosedur dalam berorganisasi, berdampak pada pelaksanaan organiasi Muhammadiyah dalam menjalankan tujuannya.

Dalam organisasi Muhammadiyah tidak ada proses controlling yang berkesinambungan untuk melakukan evaluasi dan koreksi sejak dini. Evaluasi secara bertahap akan mengurangi kesalahan dan penyimpangan yang terjadi, dan dapat segera diperbaiki sesuai dengan tujuan di awal perencanaan. Kegiatan yang sedang dilakukan hingga telah dilakukan, tidak pernah dibahas dalam lingkup musyawarah kerja, hingga 
tidak ada acuan dan pertimbangan untuk melakukan rencana program kerja di masa mendatang untuk memperbaiki ataupun mengembangan organisasi Muhammadiyah.

Persepsi masyarakat terhadap Muhamamdiyah cukup beragam. Pada umumnya masyarakat tidak tahu tentang organisasi Muhammadiyah. Sebagian besar menganggap Muhammadiyah adalah aliran, agama lain, sebagai partai politik, bahkan ada beberapa masyarakat yang menolak untuk mengisi angket, karena menganggap bahwa Muhammadiyah adalah ajaran sesat yang menghasilkan terorisme dan mengakibatkan warga melakukan bom bunuh diri. Muhammadiyah dianggap agama yang berbeda karena selalu berbeda ketika waktu pelaksanaan Idul Fitri dengan pemerintah.

Muhammadiyah hanya memiliki amal usaha di kecamatan Pangandaran, Mangunjaya dan Cijulang. Di Kecamatan Pangandaran ada SMA Muhammadiyah, SMP Muhammadiyah, SLB Muhammadiyah, dan TK ABA, sedangkan di Mangunjaya ada SMK Muhammadiyah dan di Cijulang ada PAUD. Namun, di kecamatan lainnya Muhammadiyah tidak memiliki amal usaha apapun. Pada umumnya masyarakat kurang tahu keberadaan amal usaha Muhammadiyah dalam bidang pendidikan selain yang ada di kecamatan Pangandaran. Dakwah dalam bentuk pengajian di setiap kecamatan dulu pernah ada, namun akhir-akhir ini tidak pernah diadakan kembali. Kegiatan pengajian yang aktif hanya kecamatan tertentu saja, yakni di Mangunjaya, Pangandaran, dan Sidamulih. Itu pun lebih banyak warga Muhamamdiyah daripada masyarakat sekitar. Ada beberapa masyarakat yang berpersepsi bahwa pengajian itu hanya untuk intern Muhammadiyah saja, bukan untuk masyarakat umum. Peran Muhammadiyah dalam bidang sosial hanya tampak di beberapa kecamatan saja, yaitu Mangunjaya, Pangandaran, dan Sidamulih. Pada kecamatan lainnya kegiatan sosial yang dilakukan oleh Muhammadiyah kurang terasa. Muhammadiyah tidak terlalu aktif dalam kegiatan kebencanaan, hanya segelintir orang saja.

Kegiatan dalam Muhammadiyah diniatkan dengan tujuan sebagai sarana dan wahana dakwah islamiyah amar ma'ruf nahi mungkar, beraqidah Islam dan bersumber kepada Al- Qur'an dan Sunnah. Namun, kadang hanya untuk kepentingan seseorang atau sekelompok orang. Berdasarkan hasil wawancara dengan guru ada sebagian tokoh Muhammadiyah yang meminta dana SMA untuk kepentingan pribadi. Bahkan sebagian menduga bahwa sebagian tokoh Muhammadiyah yang menghambat proses balik nama pada tanah wakaf menjadi atas nama Muhammadiyah memiliki tendensi maksud tertentu. Padahal dari pemilik tanah yang mewakafkan bersedia memfasilitasi balik nama 
menjadi Muhammadiyah. Tanah wakaf yang menjadi salah satu aset Muhammadiyah untuk mengembangkan amal usaha pada kahirnya tidak diberdayakan secara masimal, bahkan cenderung terbengkalai dan akhirnya digunakan oleh orang lain untuk beramal usaha. Dampaknya adalah minimnya pemasukan untuk kas PDM Pangandaran, bahkan terkadang sampai minus. Untuk dana kegiatan sering mencari dana dari pemerintahan atau mencari kerjasama dengan orang lain. Itu pun hanya segelintir orang saja. Sebagian besar menjadikan alasan ketiadaan biaya untuk tidak melakukan kegatan dan merumuskan program kerja.

Muhammadiyah sebagai gerakan tajdid, gerakan reformasi yang siap pada perubahan jaman, namun banyak tokoh-tokoh Muhamamdiyah yang enggan berubah. Adanya penelitian sebagai evaluasi dakwah Muhammadiyah di Pangandaran pun dianggap sebagai sesuatu hal yang kurang penting pada sebagian orang. Dinamika masyarakat yang kompleks tidak membuat sebagian tokoh-tokoh Muhammadiyah mengubah gaya pendekatan pada masyarakat agar lebih mudah dipahami oleh masyarakat yang awam.

Pendekatan pada masyarakat untuk mengembangkan dakwah Muhammadiyah, idealnya ada sumbahsih ide, tenaga, dan dana dari semua warga Muhammadiyah. Namun, pada kenyataannya, sebagian warga lebih melihat sisi keuntungannya bagi diri pribadi, yang diukur secara materi (uang), bukan tentang bagaimana menjadi amar ma'ruf nahi mungkar. Bila dahulu pak Dahlan mu menjual semua kekayaannya untuk bisa menghidupi/ menggaji guru-guru, namun di Pangandaran banyak guru yang dipotong gajinya, atau bahkan gajinya tertunda dan tidak ada, karena dana yang ada diminta untuk alasan kegiatan Muhammadiyah (Kegiatan Muhammadiyah yang tidak terprogram secara jelas dan tidak ada bukti laporannya baik secara materi maupun esensinya).

\section{KESIMPULAN}

Warga Muhammadiyah di Pangandaran perlu membuka hati kembali dan memulai komunikasi interpersonal dengan lapang dada dan pikiran terbuka antar semua majelis, ortom, lembaga, badan-badan Muhammadiyah. Warga Muhammadiyah di Pangandaran perlu memulai kembali untuk terlibat dalam setiap kegiatan manajemen organisasi. Terlibat dalam proses perencanaan, organizing, actuating, dan controlling. Harapannya adalah adanya persepsi masyarakat yang baik tanpa kesalahpahaman dan salah persepsi terhadap organisasi Muhammadiyah di Pangandaran. 


\section{REFERENSI}

Anggarasari, N. H. ( 2012). Pelatihan Komunikasi Interpersonal untuk Mengurangi Rasa Malu. Jurnal Intervensi Psikologi, Vol 4 No 1, E ISSN 2579 - 4337.

Fachruddin. (2009). MANAJEMEN PEMBERDAYAAN DALAM PENINGKATAN MUTU PENDIDIKAN ISLAM DI INDONESIA. Ta'dib, Vol 12, No 1 (2009) http://ecampus.iainbatusangkar.ac.id/ojs/index.php/takdib/article/view/155.

M.S, A. L. (1997). Komunikasi Antarpribadi. Yogyakarta: Kanisius.

RA, R. Y. (2005). HUBUNGAN ANTARA KOMITMEN ORGANISASI DAN IKLIM ORGANISASI DENGAN KEPUASAN KERJA KARYAWAN UNIVERSITAS MUHAMMADIYAH SURAKARTA. BENEFIT, Vol 9 No 2 Desember 2005.

Rakhmat, J. (2005). Psikologi Komunikasi. Bandung: Remadja Rosdakarya.

SYAHID, I. N. (2017). Kinerja Lima Pilar Total Quality Management di KUD Musuk Kabupaten Boyolali. . Solo: Other thesis, Universitas Sebelas Maret.

Widoyoko, E. ( 2015). Evaluasi program pembelajaran (edisi ke-7). . Yogyakarta: Pustaka Pelajar. 